\title{
$\beta$-pyrrole substituted porphyrin-pyrene dyads using vinylene spacer: Synthesis, characterization and photophysical properties
}

\author{
P SILVIYA REETA, RAVI KUMAR KANAPARTHI and L GIRIBABU* \\ Inorganic and Physical Chemistry Division, CSIR-Indian Institute of Chemical Technology, Uppal Road, \\ Tarnaka, Hyderabad 500 607, India \\ e-mail: giribabu@iict.res.in
}

MS received 27 June 2012; revised 12 September 2012; accepted 27 September 2012

\begin{abstract}
We have designed and synthesized donor-acceptor conjugates having donor pyrene at the pyrrole$\beta$ position of either free-base porphyrin or $\mathrm{Zn}$ (II) porphyrin using vinylene spacer. Both the dyads have been completely characterized by elemental analysis, MALDI-MS, UV-Vis., and fluorescence (steady state and timeresolved) spectroscopies as well as cyclic voltammetry. The absorption maxima of both dyads are red-shifted by $8-12 \mathrm{~nm}$. The ground state properties showed that there exist minimum $\pi-\pi$ interaction between the aromatic subunits of these D-A systems. Quenched emission was observed in both the dyads when excited at $290 \mathrm{~nm}$. The quenched emission explained in terms of intramolecular excitation energy transfer competes with the photo-induced electron transfer reaction in these D-A system.
\end{abstract}

Keywords. Porphyrin; pyrene; hydrocarbon; $\pi-\pi$ interactions; energy.

\section{Introduction}

Excitation energy transfer (EET) and photo-induced electron transfer (PET) reactions are essential processes for mimicking natural photosynthesis, ${ }^{1-4}$ opto-electronic applications, ${ }^{5,6}$ biological system, ${ }^{7,8}$ excitonic solar cells and medicinal application such as photodynamic therapy. ${ }^{9-11}$ Intramolecular EET and PET systems between two chromophores involving the porphyrin chromophore have received much attention in elucidation of the natural photosynthetic system. ${ }^{12-14}$ A great variety of porphyrin-based donor-acceptor systems in which a porphyrin or a metalloporphyrin is covalently/noncovalently linked to either an energy donor or an acceptor were reported in order to study the intramolecular EET and PET reactions. Majority of these porphyrin based donor-acceptor systems are having either a donor or an acceptor at meso phenyl position of tetraphenyl porphyrins and a few systems at the axial position/s of resident metallo/metalloid ion of porphyrin. ${ }^{15-18}$ In contrast, energy or electron acceptors such as fullerenes at pyrrole- $\beta$ position of a porphyrin were also reported in the literature. ${ }^{19-21}$ However, energy or electron donor at pyrrole- $\beta$ position of a porphyrin is not reported in the literature to the best of our knowledge. Here, we have designed a porphyrin-based donor-acceptor system having a pyrene donor at pyrrole- $\beta$ position

*For correspondence of either free-base or $\mathrm{Zn}(\mathrm{II})$ porphyrin using vinylene spacer for the first time. Both free-base and $\mathrm{Zn}$ (II) dyads are completely characterized by using $\mathrm{CHN}$ analysis, MALDI-MS, UV-Vis., fluorescence (both steady state and time-resolved) spectroscopies as well as cyclic voltammetry. The structure of the dyads is shown in scheme 1.

\section{Experimental}

All chemicals and reagents were purchased from Aldrich and used as such. The solvents are of commercial grade and purified prior to use. ${ }^{22}$ ACME silica gel (100-200 mesh) was used for column chromatography and thin-layer chromatography was performed on Merck-precoated silica gel $60-\mathrm{F}_{254}$ plates. Either gravity or flash chromatography was used for compound purification. Where as a dual solvent system was used, gradient elution was employed, and the major band was collected. All porphyrin reactions were carried out under nitrogen or argon atmosphere using dry degassed solvents, and the apparatus was shielded from ambient light.

\subsection{Synthesis}

The compounds 5,10,15,20-tetraphenyl porphyrin $\left(\mathbf{H}_{\mathbf{2}} \mathbf{L}^{\mathbf{1}}\right)$, 5,10,15,20-tetraphenyl porphyrinato zinc(II) $\left(\mathbf{Z n L}^{\mathbf{1}}\right)$, and triphenyl[[(5,10,15,20-tetraphenyl porphyrin- 


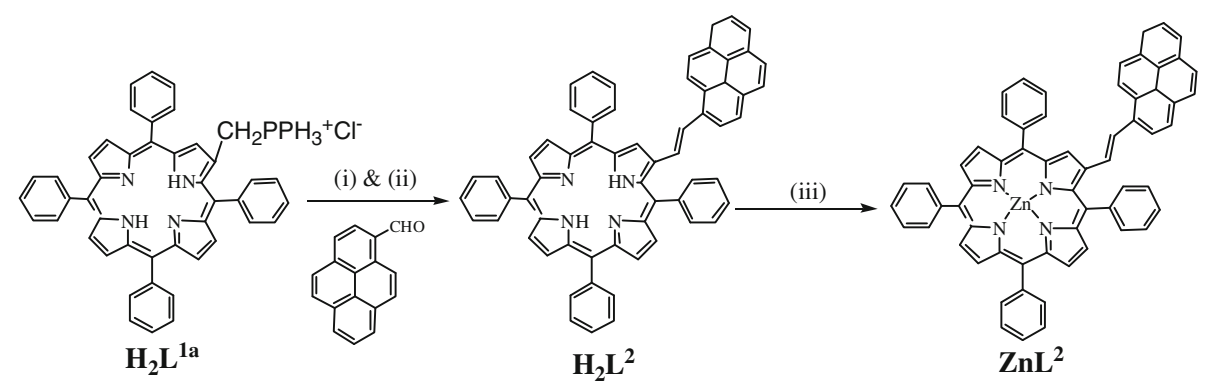

(i) $\mathrm{DBU}, \mathrm{CH}_{2} \mathrm{Cl}_{2}$, RT (ii) $\mathrm{I}_{2}$ Isomerization (iii) $\mathrm{Zn}(\mathrm{OAc})_{2} \cdot 2 \mathrm{H}_{2} \mathrm{O}, \mathrm{CH}_{3} \mathrm{OH} / \mathrm{CHCl}_{3}$, Reflux

Scheme 1. Synthetic scheme of porphyrin-pyrene dyads.

2-yl]methyl] phosphonium chloride $\left(\mathbf{H}_{2} \mathbf{L}^{\mathbf{1 a}}\right)$ were synthesized according to the reported procedures in the literature. ${ }^{23,24}$

2.1a Synthesis of 5,10,15,20-tetraphenyl-2-(2-pyren-1$y$ l-vinyl)-porphyrin $\left(\boldsymbol{H}_{\mathbf{2}} \boldsymbol{L}^{2}\right)$ : This compound was synthesized by using Wittig-Horner reaction. ${ }^{25} \mathbf{H}_{2} \mathbf{L}^{1 \mathbf{a}}$ $(0.100 \mathrm{~g}, 0.108 \mathrm{mmol}), 1$-pyrenecarboxaldehyde $(0.0028 \mathrm{~g}$, $0.118 \mathrm{mmol})$ and DBU $(0.090 \mathrm{~g}, 0.592 \mathrm{mmol})$ were dissolved in $20 \mathrm{ml}$ of $\mathrm{CH}_{2} \mathrm{Cl}_{2}$ and stirred magnetically at $\mathrm{RT}$ for $5 \mathrm{~min}$. The reaction mixture was subjected to flash chromatography using $\mathrm{CH}_{2} \mathrm{Cl}_{2} / \mathrm{Hexane} 1: 1$ as eluant and the solvent was evaporated to dryness. The obtained solid material was redissolved in $20 \mathrm{ml}$ of $\mathrm{CH}_{2} \mathrm{Cl}_{2}$. To this, about $0.002 \mathrm{~g}$ of $\mathrm{I}_{2}$ was added for cis-trans isomerization and the reaction mixture was stirred at RT for $16 \mathrm{~h}$. After completion of the reaction, the reaction mixture was washed with $1 \mathrm{M} \mathrm{Na} \mathrm{S}_{2} \mathrm{O}_{3}$ solution in water and extracted with $\mathrm{CH}_{2} \mathrm{Cl}_{2}$. The solvent was removed and the obtained solid material was subjected to silica gel chromatography using $\mathrm{CH}_{2} \mathrm{Cl}_{2}$ /hexane (1:1) as eluant to get the desired product in $80 \%$ yield. Anal. Calcd. for $\mathrm{C}_{60} \mathrm{H}_{42} \mathrm{~N}_{4}, \%$ (842.34): Calculated C, 88.33; H, 5.02; N, 6.65. Found C, 88.35; $\mathrm{H}, 5.01 ; \mathrm{N}, 6.63$. MALDI-MS (m/z): $\mathrm{C}_{60} \mathrm{H}_{42} \mathrm{~N}_{4}$ [842]: $842(100 \%) .{ }^{1} \mathrm{H}$ NMR $\left(\mathrm{CDCl}_{3}, \delta \mathrm{ppm}\right): 9.20(\mathrm{~s}, 1 \mathrm{H})$; $8.75(\mathrm{~m}, 6 \mathrm{H}) ; 8.55(\mathrm{~d}, 2 \mathrm{H}, \mathrm{J}=8.0 \mathrm{~Hz}) ; 8.30(\mathrm{~m}, 2 \mathrm{H})$; $8.20(\mathrm{~m}, 8 \mathrm{H}) ; 8.15(\mathrm{~m}, 5 \mathrm{H}) ; 7.75(\mathrm{~m}, 12 \mathrm{H}), 7.35(\mathrm{~d}, 1 \mathrm{H}$, $\mathrm{J}=6.2 \mathrm{~Hz}), 7.15(\mathrm{~d}, 1 \mathrm{H}, \mathrm{J}=6.2 \mathrm{~Hz})$ and $-2.72(\mathrm{~b}, 2 \mathrm{H})$.

2.1b Synthesis of 5,10,15,20-tetraphenyl-2-(2-pyren1-yl-vinyl)-porphyrinato zinc(II) $\quad\left(\mathbf{Z n} \mathbf{L}^{\mathbf{2}}\right): \mathbf{H}_{\mathbf{2}} \mathbf{L}^{\mathbf{2}}$ $(0.100 \mathrm{~g}, 0.12 \mathrm{mmol})$ and $\mathrm{ZnO}(\mathrm{Ac})_{2} .2 \mathrm{H}_{2} \mathrm{O}$ were dissolved in $25 \mathrm{ml}$ of $\mathrm{CHCl}_{3} / \mathrm{CH}_{3} \mathrm{OH}$ mixture. The resultant reaction mixture was refluxed until there is a change in Q-band absorption. The solvent was removed and washed with water. The obtained solid material was subjected to silica gel column chromatography using $\mathrm{CH}_{2} \mathrm{Cl}_{2}$ as eluent. The solvent front running band was collected and recrystallized with $\mathrm{CH}_{2} \mathrm{Cl}_{2} /$ hexane mixture to get $\mathbf{Z n L ^ { 2 }}$ in $95 \%$ yield. Anal. Calcd. for $\mathrm{C}_{62} \mathrm{H}_{38} \mathrm{~N}_{4} \mathrm{Zn}, \%$ (902.24): Calculated C, 82.34; H, 4.24; N, 6.20. Found C, 82.30; H, 4.20; N, 6.20. ${ }^{1} \mathrm{H}$ NMR $\left(\mathrm{CDCl}_{3}, \delta \mathrm{ppm}\right): 9.30(\mathrm{~s}, 1 \mathrm{H}) ; 8.90(\mathrm{~m}, 6 \mathrm{H}) ; 8.55(\mathrm{~d}$, $2 \mathrm{H}, \mathrm{J}=8.0 \mathrm{~Hz}) ; 8.35(\mathrm{~m}, 2 \mathrm{H}) ; 8.25(\mathrm{~m}, 8 \mathrm{H}) ; 8.15(\mathrm{~m}$, $5 \mathrm{H}) ; 7.80(\mathrm{~m}, 12 \mathrm{H}), 7.35(\mathrm{~d}, 1 \mathrm{H}, \mathrm{J}=6.2 \mathrm{~Hz}), 7.15(\mathrm{~d}$, $1 \mathrm{H}, \mathrm{J}=6.2 \mathrm{~Hz})$.

\subsection{Methods}

The UV-Visible spectra were recorded with Ocean Optics spectrophotometer for $1 \times 10^{-6} \mathrm{M}$ (porphyrin Soret band) and $5 \times 10^{-5} \mathrm{M}$ (porphyrin Q bands) solutions. Steady state fluorescence spectra were recorded using a Spex model Fluorlog-3 spectrofluorimeter for solutions having optical density at the wavelength of excitation $\left(\lambda_{\mathrm{ex}}\right) \approx 0.11$. The fluorescence quantum yields $(\phi)$ were estimated by integrating the fluorescence bands and by using either 5,10,15,20-tetraphenyl porphyrin $\left(\mathrm{H}_{2} \mathrm{TPP}\right)\left(\phi=0.13\right.$ in $\left.\mathrm{CH}_{2} \mathrm{Cl}_{2}\right)$, or 5,10,15,20-tetraphenyl porphyrinato zinc(II) ([ZnTPP]) $\left(\phi=0.036\right.$ in $\mathrm{CH}_{2} \mathrm{Cl}_{2}$ ) as the standards. ${ }^{26}$ Timeresolved fluorescence measurements have been carried out using HORIBA jobin yvon spectrofluorometer. Briefly, the samples were excited at $405 \mathrm{~nm}$ and the emission was monitored at $655 \mathrm{~nm}$, in case of porphyrin. Whereas in case of pyrene it was excited at $290 \mathrm{~nm}$ and the emission was monitored at $375 \mathrm{~nm}$. The count rates employed were typically $10^{3}-10^{4} \mathrm{~s}^{-1}$. Deconvolution of the data was carried out by the method of iterative reconvolution of the instrument response function and the assumed decay function using DAS-6 software. The goodness of the fit of the experimental data to the assumed decay function was judged by the standard statistical tests (i.e., random distribution of weighed residuals, the autocorrelation function and the values of reduced $\chi^{2}$ ). MALDI-MS spectra were recorded on a TO-4X KOMPACT SEQ, KARTOS, UK, mass spectrometer. Major fragmentations are given as percentages relative to the base peak 
intensity. ${ }^{1} \mathrm{H}$ NMR spectra were obtained at $300 \mathrm{MHz}$ using a Brucker 300 Avance NMR spectrometer running X-WIN NMR software. The chemical shifts are relative to tetramethylsilane (TMS). Differential pulse voltammetric measurements were performed on a PCcontrolled $\mathrm{CH}$ instruments model CHI 620C electrochemical analyzer. The electrochemical experiments were performed on $1 \mathrm{mM}$ porphyrin dyads solution in dichloromethane solvent using $0.1 \mathrm{M}$ tetrabutyl ammonium perchlorate (TBAP) as supporting electrolyte. The working electrode is glassy carbon, standard calomel electrode (SCE) is reference electrode and plantinum wire is an auxillary electrode.

\section{Results and discussion}

\subsection{Ground state properties}

Scheme 1 illustrates the synthesis of both the dyads. The free-base dyad was synthesized by adopting Wittig-Horner reaction and followed by zinc metal insertion into the porphyrin cavity to get the corresponding zinc dyad. Preliminary characterization was done by using elemenal analysis and MALDI-MS spectroscopy. The MALDI-MS spectrum $\mathbf{H}_{2} \mathbf{L}^{2}$ is shown in figure 1 and it consists of molecular ion peak 842, which ascribe to the presence of corresponding dyad molecule. ${ }^{1} \mathrm{H}$ NMR spectra data of $\mathbf{H}_{2} \mathbf{L}^{2}$ and $\mathbf{Z n} \mathbf{L}^{2}$ and $\mathbf{P y}-\mathbf{C H O}$ are displayed in figure 2. A comparison of these spectra with those of $\mathbf{H}_{\mathbf{2}} \mathbf{L}^{\mathbf{1}}, \mathbf{Z n L}^{\mathbf{1}}$ and $\mathbf{P y}-\mathbf{C H O}$ reveals that the resonance positions of the various protons present either on the porphyrin macrocycle or the pyrene subunit are not shifted considerably upon linking the two chromphores via the vinylene spacer. This is reasonable if one considers that the two aromatic rings are at 'trans' configuration with respect to the $\mathrm{C}=\mathrm{C}$ spacer, avoiding the steric interaction. The two doublets appeared at 7.15 and $7.35 \mathrm{ppm}$ belongs to the vinylene protons, which indicates the formation of the dyad.

Figure 3 illustrates the differential pulse voltammograms of the dyads investigated in this study and the corresponding data summarized along with their individual constituents are presented in table 1 . As can be seen from the figure 3 and table 1 , each investigated new dyad shows up to two reductions and three oxidation peaks under the experimental conditions employed in this study. Wave analysis suggested that, in general, while the first two reduction steps and first two oxidation steps are reversible, one-electron transfer reactions, the subsequent steps are, in general, either quasireversible or totally irreversible. While the first reduction peak in both dyads corresponds to the reduction of the porphyrin ring, the remaining extensively overlapping peaks are assigned to electron addition to the porphyrin/pyrene moiety in each case. Similarly, the peaks occurring at potentials that are less anodic than $1.25 \mathrm{~V}$ are ascribed to successive one-electron oxidations of the porphyrin parts of dyads; the peak occurring at more anodic potential represents the oxidation of the appended pyrene moiety. The electrochemical data suggests that the redox potentials of the dyads are close to those of the corresponding reference compounds.

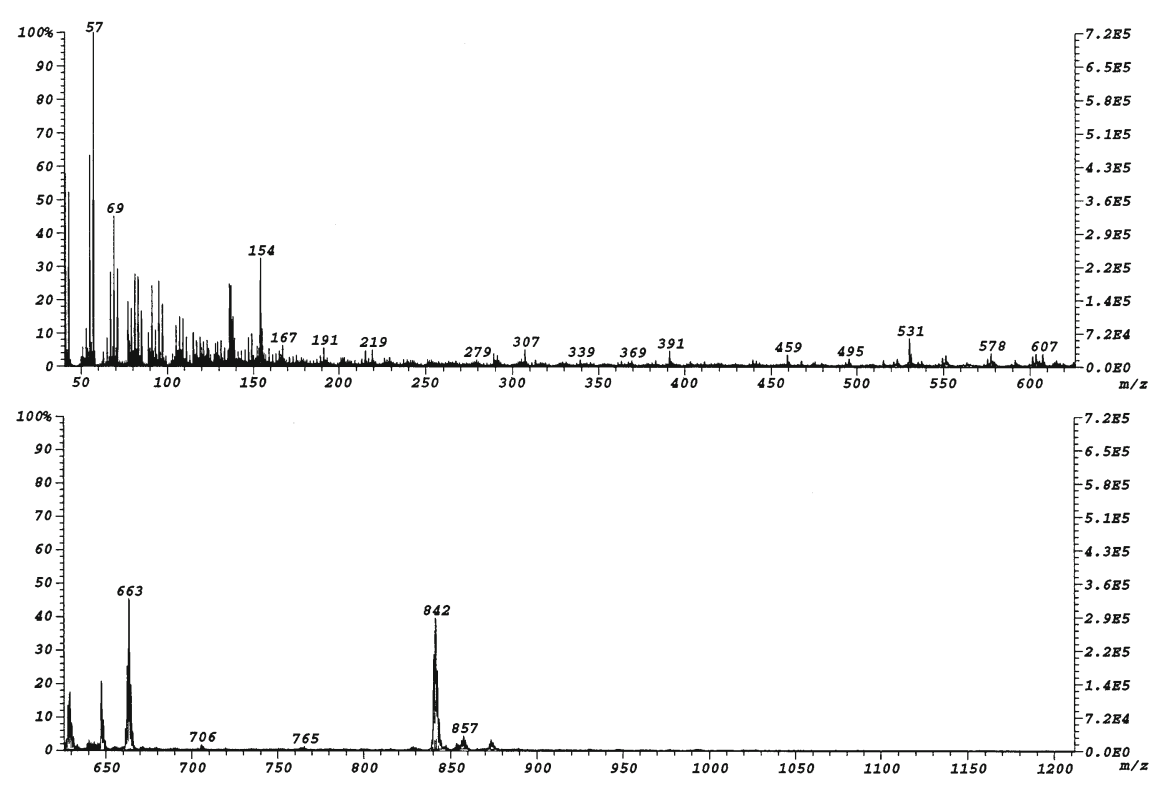

Figure 1. MALDI-MS spectrum of $\mathbf{H}_{2} \mathbf{L}^{2}$. 


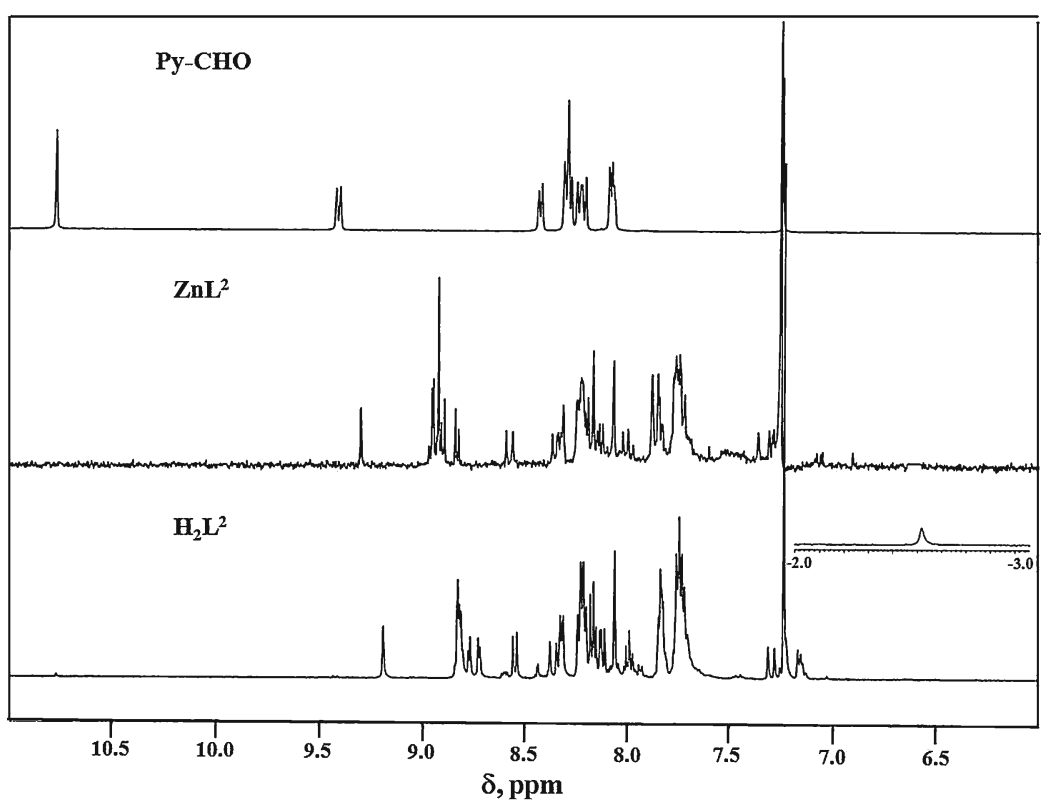

Figure 2. ${ }^{1} \mathrm{H}$ NMR spectra of Py-CHO, $\mathbf{Z n L} \mathbf{L}^{2}$ and $\mathbf{H}_{2} \mathbf{L}^{2}$ in $\mathrm{CDCl}_{3}$.

Figure 4 displays the absorption spectrum of $\mathbf{H}_{2} \mathbf{L}^{2}$ measured in dichloromethane solvent. The wavelength of maximum absorbance $\left(\lambda_{\max }\right)$ and molar extinction coefficients $(\log \varepsilon)$ values of the both the dyads and their constituent individual components (i.e., $\mathbf{H}_{\mathbf{2}} \mathbf{L}^{\mathbf{1}}$, $\mathbf{Z n L}^{\mathbf{1}}$ and $\mathbf{P y}-\mathbf{C H O}$ ) as obtained from the UV-Vis., studies are summarized in table 1. Comparison of the spectrum in figure 4 and data in table 1 suggests that the appended pyrene chromophore in these dyads absorbs dominantly between ca. 230 and $350 \mathrm{~nm}$ region in which porphyrin part of each molecule show

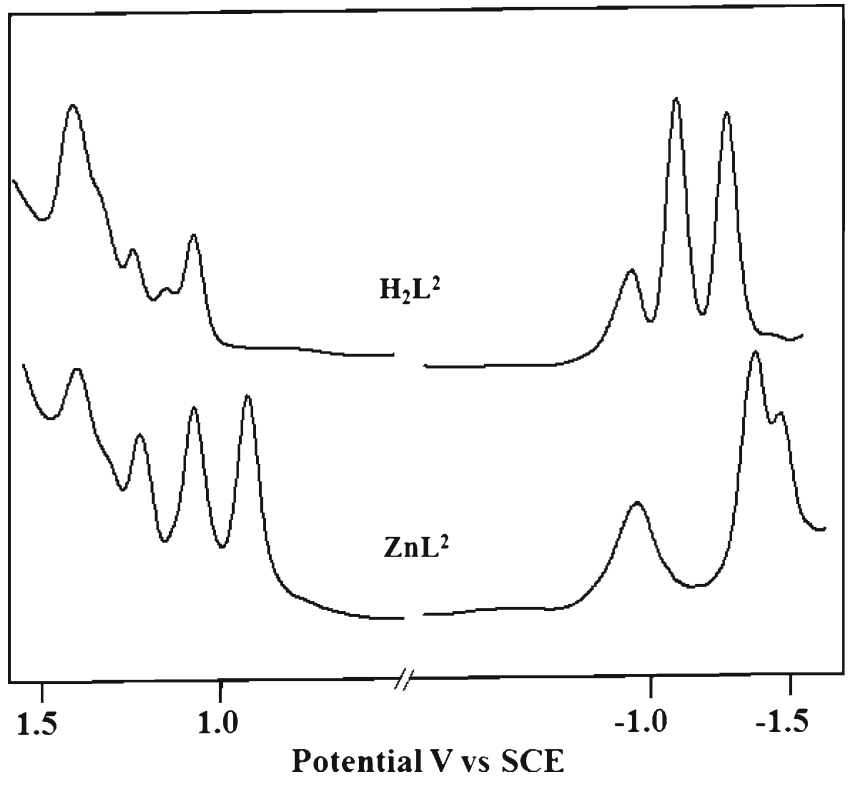

Figure 3. Differential Pulse Voltammogrammes in $\mathrm{CH}_{2} \mathrm{Cl}_{2}$ and $0.1 \mathrm{M}$ TBAP. its so-called $\mathrm{N}$ and $\mathrm{L}$ bands. Nonetheless, the peak at $\sim 287 \mathrm{~nm}$ for each dyad corresponds largely to the absorbance of the pyrene moiety because the $\mathrm{N}$ and $\mathrm{L}$ bands are quite weak compared to the pyrene absorbance in this wavelength region. Analogously, porphyrin part of these dyads shows either four $\left(\mathbf{H}_{2} \mathbf{L}^{2}\right)$ or two $\left(\mathbf{Z n L}^{\mathbf{2}}\right)$ Q-bands in the wavelength region (500$700 \mathrm{~nm}$ ) where the pyrene moiety of the dyad molecules does not absorb. The peak at around $420 \mathrm{~nm}$ is Soret band of porphyrin part of the dyads. Spectral data given in the table 1 further reveal that the absorption maxima of both dyads are red-shifted by $8-12 \mathrm{~nm}$ in comparison with the corresponding absorption bands in $\mathbf{H}_{\mathbf{2}} \mathbf{L}^{\mathbf{1}}$ and $\mathbf{Z n L}{ }^{1}$. Similar red-shifted bands are also observed in other pyrrole- $\beta$ substituted porphyrins. ${ }^{20,24}$ Finally, it was observed that the $\lambda_{\max }$ and spectral shapes of the bands of both the dyads are more or less similar to those of solutions containing one equivalent of each $\mathbf{H}_{2} \mathbf{L}^{1} / \mathbf{Z n L}^{1}$ and Py-CHO.

The ground state properties and electrochemical features described above suggested that electronic communication between porphyrin and pyrene chromphores is quite negligible in these new D-A systems. More importantly, the absorption data suggests that it is possible to individually address photophysical behaviour of the porphyrin and pyrene subunits in these bichromophoric systems. This situation is unlike in previously reported porphyrin-pyrene conjugates, where pyrene subunit/s is directly connected to the porphyrin macrocycle, but is quite similar to the porphyrin-pyrene systems wherein the two chromophores are linked via $\mathrm{C}=\mathrm{N}$ spacer at the meso phenyl ring of tetraphenyl porphyrin as well as in $\mathrm{P}(\mathrm{V})$ porphyrin-pyrene wherein the 
Table 1. UV-visible and electrochemical data.

\begin{tabular}{|c|c|c|c|c|c|c|c|c|c|c|}
\hline \multirow{3}{*}{$\frac{\text { Compound }}{\mathbf{H}_{2} \mathbf{L}^{\mathbf{1}}}$} & \multicolumn{8}{|c|}{ Absorption, $\lambda_{\max }, \mathrm{nm}\left(\log \varepsilon, \mathrm{M}^{-1} \mathrm{~cm}^{-1}\right)^{\mathrm{a}}$} & \multicolumn{2}{|c|}{ Potential V vs. SCE ${ }^{b}$} \\
\hline & \multicolumn{5}{|c|}{ Porphyrin bands } & \multicolumn{3}{|c|}{ Pyrene bands } & \multirow{2}{*}{$\begin{array}{c}\text { Reduction } \\
-1.21,-1.51\end{array}$} & \multirow{2}{*}{$\begin{array}{l}\text { Oxidation } \\
1.01,1.39\end{array}$} \\
\hline & $\begin{array}{c}417 \\
(5.18)\end{array}$ & $\begin{array}{c}515 \\
(4.15)\end{array}$ & $\begin{array}{c}545 \\
(3.90)\end{array}$ & $\begin{array}{c}590 \\
(3.60)\end{array}$ & $\begin{array}{c}646 \\
(3.70)\end{array}$ & & - & & & \\
\hline $\mathbf{Z n L}^{1}$ & $\begin{array}{c}417 \\
(5.60)\end{array}$ & $\begin{array}{c}547 \\
(4.13)\end{array}$ & $\begin{array}{c}586 \\
(3.64)\end{array}$ & & & & - & & $-1.40,-1.71$ & $0.74,1.09$ \\
\hline Ру-CHO & & $\begin{array}{l}- \\
-\end{array}$ & & & & $\begin{array}{c}290 \\
(4.55)\end{array}$ & $\begin{array}{c}372 \\
(4.39)\end{array}$ & $\begin{array}{c}398 \\
(4.34)\end{array}$ & -1.44 & 1.53 \\
\hline $\mathbf{H}_{2} \mathbf{L}^{2}$ & $\begin{array}{c}425 \\
(5.10)\end{array}$ & $\begin{array}{c}523 \\
(4.20)\end{array}$ & $\begin{array}{c}569 \\
(4.00)\end{array}$ & $\begin{array}{c}602 \\
(3.80)\end{array}$ & $\begin{array}{c}658 \\
(3.30)\end{array}$ & $\begin{array}{c}287 \\
(4.30)\end{array}$ & $\begin{array}{c}350 \\
(4.39)\end{array}$ & $\begin{array}{c}372 \\
(4.42)\end{array}$ & $-1.13,-1.36$ & $1.07,1.23,1.52$ \\
\hline $\mathbf{Z n L}^{2}$ & $\begin{array}{c}429 \\
(5.10)\end{array}$ & $\begin{array}{c}559 \\
(4.30)\end{array}$ & $\begin{array}{c}598 \\
(4.04)\end{array}$ & & & $\begin{array}{c}287 \\
(4.40)\end{array}$ & $\begin{array}{c}349 \\
(4.42)\end{array}$ & & $-1.49,-1.60$ & $0.74,1.25,1.55$ \\
\hline
\end{tabular}

a Solvent $\mathrm{CH}_{2} \mathrm{Cl}_{2}$, error limits: $\lambda_{\max }, \pm 1 \mathrm{~nm}, \log \varepsilon, \pm 10 \%$

${ }^{\mathrm{b}} \mathrm{CH}_{2} \mathrm{Cl}_{2}, 0.1 \mathrm{M}$ TBAP; glassy carbon working electrode, standard calomel electrode is reference electrode, Pt electrode is auxillary electrode. Error limits, $\mathrm{E}_{1 / 2} \pm 0.03 \mathrm{~V}$

two chromophres are linked, via alkoxy spacer at axial sites. ${ }^{27-30}$ In fact, the whole entity functions as a modified porphyrin in the former system, the spectroscopic signatures of the porphyrin and pyrene subunits are easily identifiable in later ones. Despite the presence of a short $\mathrm{C}=\mathrm{C}$ bond separating two subunits, the $\mathrm{D}-\mathrm{A}$ systems investigated in this study seem to belong to the latter class of compounds as suggested by spectroscopic data presented above.

\subsection{Singlet state properties}

Figure 5 illustrates the steady state fluorescence spectra of the dyads along with the individual constituents measured in $\mathrm{CH}_{2} \mathrm{Cl}_{2}$ solvent and the corresponding

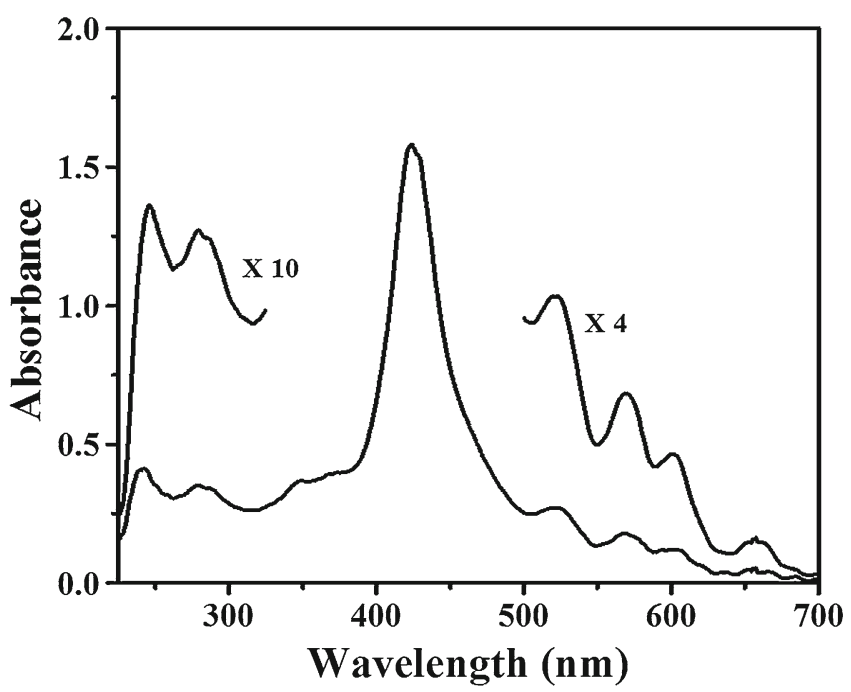

Figure 4. UV-Visible absorption spectra in $\mathrm{CH}_{2} \mathrm{Cl}_{2}$. data presented in table 2. When excited at $290 \mathrm{~nm}$ $\left(\lambda_{\max }\right.$, where pyrene absorbs predominantly), resulted quenched emission spectra in both the dyads in comparison with the fluorescence due to pyrene (Py) (figure 5a). However, when excited at $550 \mathrm{~nm}$ (porphyrin absorption), the resulted spectra are seen to be similar to those in the spectrum of either $\mathbf{H}_{\mathbf{2}} \mathbf{L}^{1}$ or $\mathbf{Z n \mathbf { L } ^ { 1 }}$ (figure 5b) except in emission maxima. The emission maxima is red-shifted, when compared to its individual constituents. A similar red-shift in emission maxima was also observed in other pyrrole- $\beta$ substituted porphyrins. ${ }^{20,31}$ The $\mathrm{E}_{0-0}(0-0$ spectroscopic transition energy) values of the pyrene $(3.56 \pm 0.05 \mathrm{eV})$ and the porphyrin $\left(1.90 \pm 0.05 \mathrm{eV}\right.$ for $\mathbf{H}_{\mathbf{2}} \mathbf{L}^{2}$ and $2.07 \pm 0.05 \mathrm{eV}$ for $\mathbf{Z n \mathbf { L } ^ { 2 }}$ ) moieties of the dyads, as estimated from an overlap of their absorption and emission spectra, were found to be in the same range as the $E_{0-0}$ values of pyrene, $\mathbf{H}_{2} \mathbf{L}^{1}$ and $\mathbf{Z n L ^ { 1 }}$, respectively.

A major difference is noticed between the fluorescence data of these dyads and those of individual constituents. The fluorescence quantum yield $(\phi)$ was similar in both the dyads when excited into the porphyrin part of each dyad in comparison with that of unlinked porphyrin (i.e., $\mathbf{H}_{\mathbf{2}} \mathbf{L}^{2} / \mathbf{Z n} \mathbf{L}^{2}, \phi=0.13 \pm 0.01$ and $0.036 \pm$ 0.001 , respectively). In contrast, quenched emission intensity was observed in both the dyads, when excited at $290 \mathrm{~nm}$ in comparison with Py. The quenching efficiency values $(Q)$,

$$
Q=\frac{\phi(P y)-\phi\left(\left(H_{2} L^{2} / Z n L^{2}\right)\right.}{\phi(P y)},
$$

where $\phi(\mathbf{P y})$ and $\phi\left(\mathbf{H}_{2} \mathbf{L}^{2} / \mathbf{Z n} \mathbf{L}^{2}\right)$ refer to the fluorescence quantum yields for $\mathbf{P y}$ and the D-A systems 


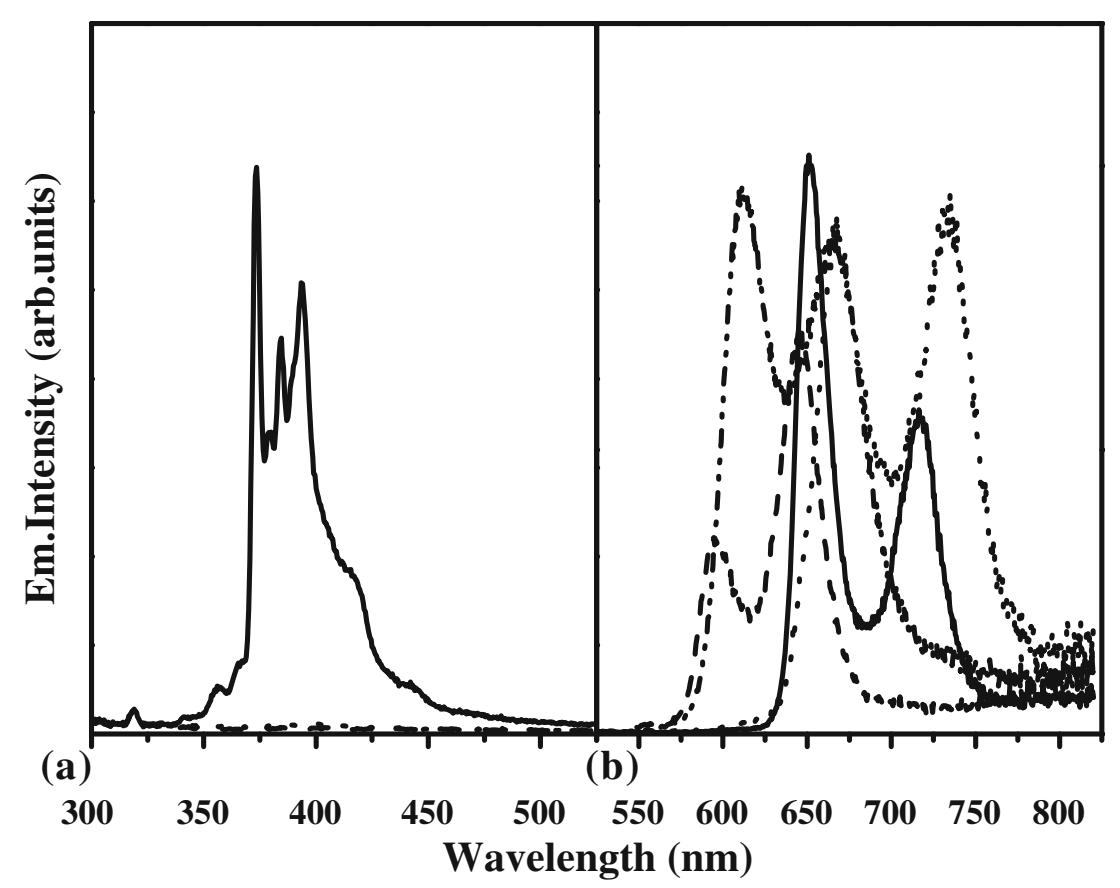

Figure 5. Fluorescence spectra of equiabsorbing solutions $\left(\mathrm{OD} \lambda_{\mathrm{ex}}=0.11\right)$

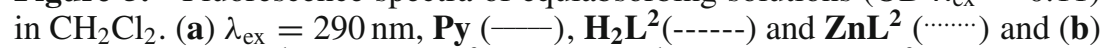

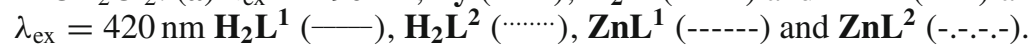

$\mathbf{H}_{2} \mathbf{L}^{2} / \mathbf{Z n L} \mathbf{L}^{2}$, respectively; $\left(\lambda_{\text {ex }}=290 \mathrm{~nm}\right)$ have been calculated for these systems in three different solvents. The quenching is more than $90 \%$ for both the dyads in all three investigated solvents. Figure 6 illustrates excited state fluorescence decay profile of both dyads collected in $\mathrm{CH}_{2} \mathrm{Cl}_{2}$ solvent, by selectively exciting the sample with two different excitation sources $\left(\lambda_{\mathrm{ex}}=290\right.$ and $405 \mathrm{~nm}$ ), where the individual subunits (pyrene and porphyrin) absorb predominantly at one wavelength. As expected, when we monitored the porphyrin emission $\left(\lambda_{\text {em }}=655 \mathrm{~nm}\right)$, the fluorescence lifetime $(\tau)$ of both the dyads $\mathbf{H}_{2} \mathbf{L}^{2}$ and $\mathbf{Z n L ^ { 2 }}$ (7.8 and $1.7 \mathrm{~ns}$, respectively) was not quenched much compared to $\mathbf{H}_{2} \mathbf{L}^{1}$ and $\mathbf{Z n L}^{\mathbf{1}}$ (8.9 and $2.05 \mathrm{~ns}$, respectively). However, on the other hand, when the pyrene emission is monitored $\left(\lambda_{\mathrm{em}}=375 \mathrm{~nm}\right)$, the fluorescence lifetime of the $\mathbf{H}_{2} \mathbf{L}^{2}$ is found to be $1.81 \mathrm{~ns}$ while $\mathbf{Z n \mathbf { L } ^ { 2 }}$ is about $1.55 \mathrm{~ns}$. It is known from the literature that the fluorescence lifetime of simple pyrene in medium polar solvents is $\geq 250 \mathrm{~ns} .{ }^{30}$ The dramatic fluorescence quenching can be perhaps understood based on the excited state electron or energy transfer from pyrene to porphyrin subunit.

Table 2. Fluorescence data. ${ }^{\mathrm{a}}$

\begin{tabular}{|c|c|c|c|c|c|c|}
\hline \multirow[b]{3}{*}{ Compound } & \multicolumn{6}{|c|}{$\lambda_{\mathrm{em}}, \mathrm{nm}(\phi, \% Q)^{\mathrm{b}}$} \\
\hline & \multicolumn{2}{|c|}{ Toluene } & \multicolumn{2}{|c|}{$\mathrm{CH}_{2} \mathrm{Cl}_{2}$} & \multicolumn{2}{|c|}{$\mathrm{CH}_{3} \mathrm{CN}$} \\
\hline & $\lambda_{\text {ex }}=290 \mathrm{~nm}$ & $\lambda_{\mathrm{ex}}=420 \mathrm{~nm}$ & $\lambda_{\mathrm{ex}}=290 \mathrm{~nm}$ & $\lambda_{\mathrm{ex}}=420 \mathrm{~nm}$ & $\lambda_{\mathrm{ex}}=290 \mathrm{~nm}$ & $\lambda_{\text {ex }}=420 \mathrm{~nm}$ \\
\hline $\mathbf{H}_{2} \mathbf{L}^{1}$ & - & $\begin{array}{c}649,715 \\
(0.110)\end{array}$ & - & $\begin{array}{c}648,715 \\
(0.110)\end{array}$ & - & $\begin{array}{c}649,715 \\
(0.120)\end{array}$ \\
\hline $\mathbf{Z n L}^{1}$ & - & $\begin{array}{c}603,655 \\
(0.032)\end{array}$ & - & $\begin{array}{c}601,647 \\
(0.036)\end{array}$ & - & $\begin{array}{c}603,655 \\
(0.033)\end{array}$ \\
\hline $\mathbf{P y}$ & $\begin{array}{c}374,394 \\
(0.069)\end{array}$ & - & $\begin{array}{c}374,394 \\
(0.090)\end{array}$ & - & $\begin{array}{c}373,393 \\
(0.070)\end{array}$ & - \\
\hline $\mathbf{H}_{2} \mathbf{L}^{2}$ & $\begin{array}{c}390 \\
(0.004,94)\end{array}$ & $\begin{array}{c}667,736 \\
(0.011)\end{array}$ & $\begin{array}{c}380 \\
(0.003,97)\end{array}$ & $\begin{array}{c}661,734 \\
(0.120)\end{array}$ & $\begin{array}{c}385 \\
(0.002,97)\end{array}$ & $\begin{array}{c}664,733 \\
(0.012)\end{array}$ \\
\hline $\mathrm{ZnL}^{2}$ & $\begin{array}{c}394 \\
(0.006,91)\end{array}$ & $\begin{array}{c}628,673 \\
(0.037)\end{array}$ & $\begin{array}{c}381 \\
(0.004,96)\end{array}$ & $\begin{array}{c}611,768 \\
(0.039)\end{array}$ & $\begin{array}{c}394 \\
(0.002,97)\end{array}$ & $\begin{array}{c}628,673 \\
(0.037)\end{array}$ \\
\hline
\end{tabular}

aError limits: $\lambda_{\text {ex }}, \pm 2 \mathrm{~nm} ; \phi, \pm 10 \% .{ }^{\mathrm{b}} Q$ is defined in equation 2 


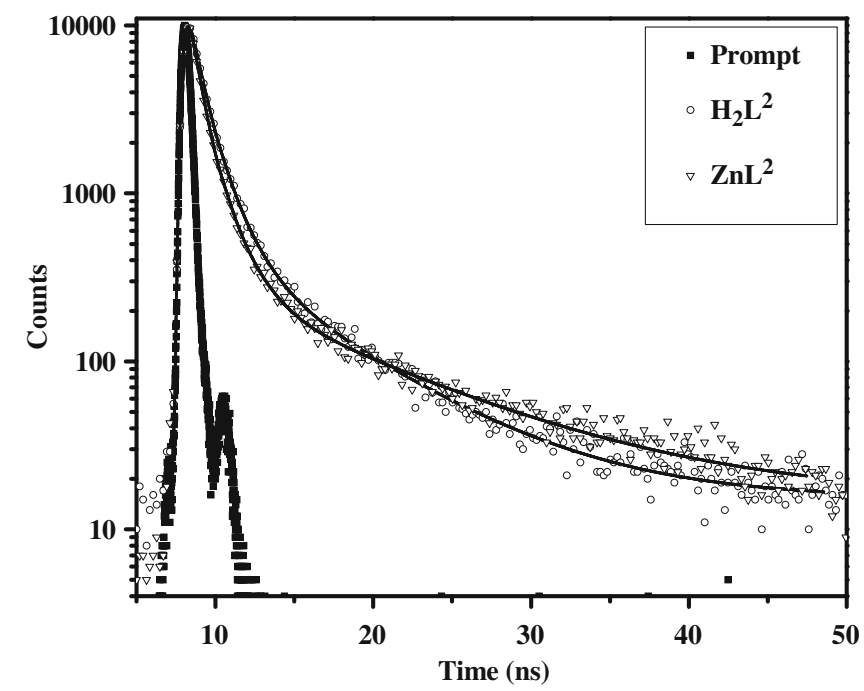

Figure 6. Fluorescence decay of $\mathbf{H}_{2} \mathbf{L}^{2}$ (o) and $\mathbf{Z n L}^{2}(\nabla)$ in $\mathrm{CH}_{2} \mathrm{Cl}_{2}$.

There exists a strong overlap between the emission of pyrene and the absorption of porphyrin in these DA conjugated systems; this suggests that fluorescence quenching of these dyads may be due to an intramolecular EET from singlet state of pyrene to the porphyrin. Indeed, excitation of $\mathrm{ca} \cdot 10^{-7} \mathrm{M}$ solution of both the dyads at $290 \mathrm{~nm}$ results in appearance of well-defined porphyrin emission bands. Furthermore, overlap of the corrected and normalized excitation spectra (emission collected at the porphyrin emission maximum, $650 \mathrm{~nm}$ ) with the corresponding absorption spectra (figure 7) reveals that the fluorescence quenching is due to the intramolecular energy transfer in these dyad systems. The efficiency of energy transfer was found to be $90 \pm$

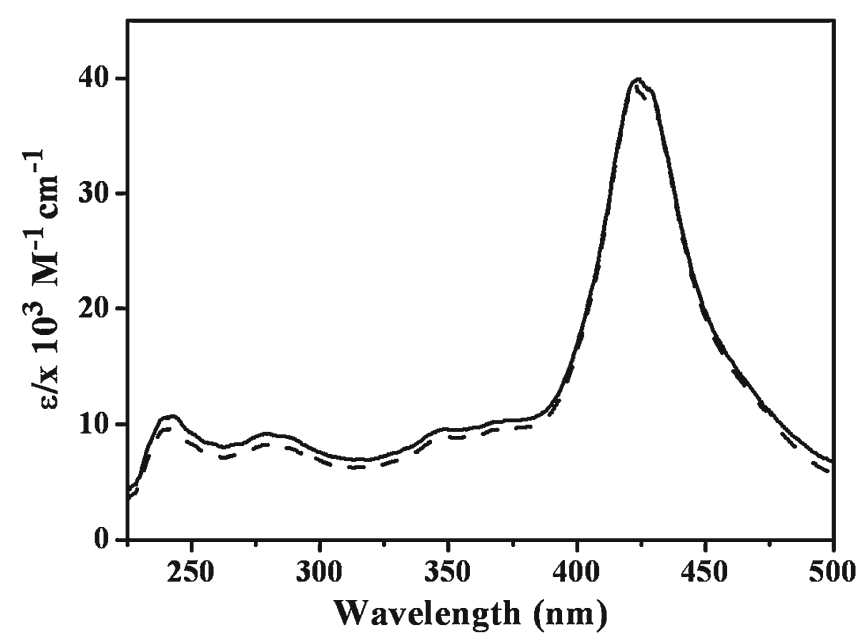

Figure 7. Overlay of excitation (------) and absorption (-) spectra of $\mathbf{H}_{2} \mathbf{L}^{2}$ in $\mathrm{CH}_{2} \mathrm{Cl}_{2}\left(\lambda_{\mathrm{em}}=765 \mathrm{~nm}\right)$. The excitation spectra were corrected for the instrument response function and were normalized with respect to the absorption spectra as described in ref. 32.
$10 \%$ in both the dyads. However, a photo-induced electron transfer reaction cannot be ruled out in these dyad systems when excited at $290 \mathrm{~nm}$ based on thermodynamic consideration. The change in free energy when PET occurs from the ground state of porphyrin part of the dyads to the singlet state of pyrene is calculated by equation (2),

$$
\begin{gathered}
\Delta \mathrm{G}\left({ }^{1} \mathrm{Py} \rightarrow \mathrm{H}_{2} \mathrm{~L}^{2} / \mathrm{ZnL}^{2}\right) \\
=\mathrm{E}_{\mathrm{CT}}\left(\mathrm{Py}^{+}\left(\mathrm{H}_{2} \mathrm{~L}^{2} / \mathrm{ZnL}^{2}\right)^{-}\right) \\
-\mathrm{E}_{0-0}\left(\mathrm{H}_{2} \mathrm{~L}^{2} / \mathrm{ZnL}^{2}\right) .
\end{gathered}
$$

$\Delta \mathrm{G}$ was found to be -1.04 and $-1.09 \mathrm{eV}$ for $\mathbf{H}_{2} \mathbf{L}^{2}$ and $\mathbf{Z n L}^{2}$, respectively. Thus, the low $\phi$ values observed upon excitation of these systems at $290 \mathrm{~nm}$ can be rationalized in terms of intramolecular EET reaction competing with PET reaction from ground state of porphyrin to the excited state of pyrene in these dyad systems.

In comparison of photophysical properties of these D-A conjugates with those of literature reported porphyrin-pyrene conujugates reveal that the energy transfer is the major pathway when pyrene is either directly connected to porphyrin macrocycle ${ }^{29,30}$ or separated from porphyrin by a short $\mathrm{C}=\mathrm{N}$ bridge. ${ }^{27} \mathrm{In}$ contrast, photo-induced electron transfer is the major pathway when pyrene is connected at the axial position/s of $\mathrm{P}(\mathrm{V})$ porphyrin via alkoxy bridge. ${ }^{28}$ In the present $\mathrm{D}-$ A systems, the energy transfer is the major pathway but one cannot neglect the electron transfer reaction also on thermodynamic consideration.

In conclusion, we have designed and synthesized D-A conjugates having pyrene hydrocarbon at the pyrrole- $\beta$ position of either free-base or $\mathrm{Zn}(\mathrm{II})$ porphyrin through $\mathrm{C}=\mathrm{C}$ bridge. Ground state properties indicate that there is a minimum electron interaction between donor pyrene subunit and acceptor porphyrin subunit. However, excited state properties showed that there is an energy transfer reaction competing with electron transfer reaction from pyrene to porphyrin when excited at pyrene absorption maxima.

\section{Acknowledgements}

We thank the Department of Science and Technology (DST, SR/S1/IC21/2008) for financial support. One of the authors PS is thankful to the Council of Scientific and Industrial Research (CSIR) for the fellowship.

\section{References}

1. McConnell I, Li G and Brudwig G W 2010 Chem. Biol. 17434

2. Guest D, Moore T A and Moore A L 2009 Acc. Chem. Rev. 421890 
3. Aratani N, Kim D and Osuka A 2009 Acc. Chem. Res. 421922

4. Albinsson B and Mårtensson J 2008 J. Photochem. Photobiol. C: Photochem. Rev. 9138

5. Senge O M, Fazekas M, Notaras E G A, Blau W J, Zawadzka M, Locos O B and Mhuircheartaigh E M 2007 Adv. Mater. 192737

6. Annoni E, Pizzotti M, Ugo R, Quici S, Morotti M, Bruschi M, Mussini P 2005 Eur. J. Inorg. Chem. 3857

7. Herrero C, Lassalle-Kaiser B, Leibl W, Rutherford A W and Aukauloo A 2008 Coord. Chem. Rev. 252 456

8. Hiraku Y, Ito K, Hirakawa K and Kawanishi S 2007 Photochem. Photobiol. 83205

9. Giribabu L, Sudhakar K and Velkannan V 2012 Curr. Sci. 102991

10. Giribabu L, Kanaparthi R K and Velkannan V 2012 Chem. Rec. 12306

11. Hirohara S, Obata M, Alitomo H, Sharyo K, Ando T, Tanihara M and Yano S 2009 J. Photochem. Photobiol. B: Biol. 9722

12. Blankenship R E, Tiede D M, Barber J, Brudvig G W, Fleming G, Ghiradi M, Gunner M R, Junge W, Kramer D M, Melis A, Moore T A, Moser C C, Nocera D G, Nozik A J, Ort D R, Parson W W, Prince R C and Sayre R T 2011 Science 332805

13. Wasielewski M R 2009 Acc. Chem. Res. 421910

14. D'Souza F and Ito O 2009 Chem. Commun. 4913

15. Kandhadi J, Kanaparthi R K and Giribabu L 2012 J. Porphyrins Phthalocyanines 16282

16. Vijendra S S and Mangalampalli R 2011 Inorg. Chem. 501713

17. Giribabu L, Kumar C V and Reddy P Y 2007 Chem. Asian J. 21574
18. Chitta R, Sandanayaka A S D, Schumacher A L, D'Souza L, Araki Y, Ito O and D'Souza F 2007 J. Phys. Chem. C 1116947

19. Lembo A, Tagliatesta P and Guild D M 2006 J. Phys. Chem A 11011424

20. Giribabu L, Kumar C V and Reddy P Y 2006 J. Porphyrins Phthalocyanines $\mathbf{1 0} 1007$

21. Ohkubo K, Imahori H, Shao J, Ou Z, Kadish K M, Chen Y, Zheng G, Pandey R K, Fujitsuka M, Ito O and Fukuzumi S 2002 J. Phys. Chem. A 10610991

22. Armarego W L F and Chai Ch L L 2003 Purification of laboratory chemicals (New York: Butterworth Heinemann)

23. Fuhrhop J H and Smith K M 1975 In Porphyrins and metalloporphyrins (ed) K M Smith (Amsterdam: Elsevier) p. 769

24. Bonfantini E E, Burrell A K, Campbell W M, Crossley M, Gosper J J, Harding M M, Officer D L and Reida D C W 2002 J. Porphyrins Phthalocyanines 6708

25. Wadsworth W S and Emmons W D $1961 \mathrm{~J}$. Am. Chem. Soc. 831733

26. Quimby D J and Longo F R 1975 J. Am. Chem. Soc. 97 5111

27. Poddutoori P K and Maiya B G 2003 Indian J. Chem. 42A 2198

28. Hirakawa K and Segawa H 1999 J. Photochem. Photobiol A: Chem. 12367

29. Lin Z-M, Feng W-Z and Leung H-K 1991 Chem. Commun. 209

30. Birks J B 1970 Photophysics of aromatic molecules (New York: Wiley/Interscience) Chapter 7

31. Reeta P S, Kandhadi J and Giribabu L 2010 Tetrahedron Lett. 512865

32. Giribabu L and Maiya B G 1999 Res. Chem. Intermed. 25769 